Erratum

\title{
Erratum: Pferschy-Wenzig, E.-M.; et al. Does a Graphical Abstract Bring More Visibility to Your Paper? Molecules 2016, 21, 1247
}

\author{
Eva-Maria Pferschy-Wenzig ${ }^{1}$, Ulrich Pferschy ${ }^{2}$, Dongdong Wang ${ }^{3}$, Andrei Mocan ${ }^{4}$ \\ and Atanas G. Atanasov $3,5, *$ \\ 1 Institute of Pharmaceutical Sciences, Department of Pharmacognosy, University of Graz, \\ Universitaetsplatz 4/1,8010 Graz, Austria; eva-maria.wenzig@uni-graz.at \\ 2 Department of Statistics and Operations Research, University of Graz, Universitaetsstrasse 15, 8010 Graz, \\ Austria; ulrich.pferschy@uni-graz.at \\ 3 Department of Pharmacognosy, University of Vienna, 1090 Vienna, Austria; dongdong.wang@univie.ac.at \\ 4 Department of Pharmaceutical Botany, Iuliu Hațieganu University of Medicine and Pharmacy, \\ 400012 Cluj-Napoca, Romania; mocan.andrei@umfcluj.ro \\ 5 Institute of Genetics and Animal Breeding of the Polish Academy of Sciences, 05-552 Jastrzebiec, Poland \\ * Correspondence: atanas.atanasov@univie.ac.at; Tel.: +43-1-4277-55231
}

Academic Editor: Derek J. McPhee

Received: 25 November 2016; Accepted: 26 November 2016; Published: 6 December 2016

The authors wish to make the following change to their paper [1]. The symbol "\%" in the last column of Table 2 is incorrect. The numbers are actually ratios so in order to obtain percentages, the numbers should be multiplied by 100 .

We apologize for any inconvenience caused to the readers by this mistake. The manuscript will be updated and the original will remain online on the article webpage.

\section{Reference}

1. Pferschy-Wenzig, E.-M.; Pferschy, U.; Wang, D.; Mocan, A.; Atanasov, A.G. Does a Graphical Abstract Bring More Visibility to Your Paper? Molecules 2016, 21, 1247. [CrossRef] [PubMed]

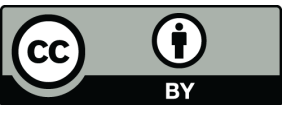

(C) 2016 by the authors; licensee MDPI, Basel, Switzerland. This article is an open access article distributed under the terms and conditions of the Creative Commons Attribution (CC-BY) license (http://creativecommons.org/licenses/by/4.0/). 